\title{
REAVALIAÇAOO DO BARBEXACLONE EM 20 PACIENTES EPILETICOS
}

\author{
CLOVIS OLIVEIRA * \\ ISMAR WERNANDES * \\ JOB: MAURO DE LIMA **
}

Em continuação aos estudos sobre a eficácia do barbexaclone nas crises convulsivas em crianças, apresentamos neste trabalho uma avaliação durante um período de até 30 meses de seguimento, analisando os resultados terapêuticos e o surgimento de efeitos colaterais.

A associação do fenobarbital com o ciclo-hexil-aminopropano (CHP) já demonstrou seu valor terapêutico como antiepilético há bastante tempo ${ }^{10}$. O leve estimulante do sistema nervoso central (SNC) que é o CHP, visa a diminuir ou abolir a sonolência que comumente aparece nos pacientes em uso de barbitúricos. Estes dois fatores, a eficácia terapêutica e diminuição e/ou aboliçăo do efeito colateral, foram já demonstrados pela experiência de diversos autores $2,3,4,5,6,7,8,9,10,11$. Contudo, um novo aspecto surge como efeito terapêutico do barbexaclone que é a melhora do distúrbio do comportamento observado em vários pacientes de modo significativo. Esta melhora, segundo nosso ponto de vista, não seria devida somente ao controle das crises, mas a uma ação especifica do ciclo-hexil-aminopropano ${ }^{\circ}$. Isto ainda merece estudos aprofundados enfocando este problema no que concerne a este aspecto. Estamos interessados atualmente na avaliação do CHP isolado nos casos de disfunção cerebral mínima.

\section{MATERIAL E METODOS}

Nosso material é constituído de 20 pacientes de 3 a 12 anos de idade, de ambos os sexos (12 meninas e 8 meninos), acompanhados por um periodo que varia de 11 a 30 meses (Tabelas 1 e 4). Fstes pacientes săo provenientes de um grupo maior de 40 que já foram avaliados em trabalho anterior durante um perfodo de 3 a 15 meses. Portanto, selecionamos aqueles que apresentaram condiçōes de reavaliaça satisfatórias. Devemos ainda considerar que o grupo estudado fol formado por pacientes virgens de tratamento e pacientes que năo estavam nbtendo melhoras com a terapeutica usual.

Destes pacientes, 13 (65\%) fizeram uso exclusivo do barbexaclone* em regime monoterapeutico, enquanto que 7 (35\%) fazlam uso, geralmente, de mais uma droga antiepllética associađa. Fstes ultimos tinham as doses terapêticas diminuidas em relaçăo as habitualmente. utilizadas.

Trabalho realizado no Instituto de Neurologia Deolindo Couto da UFRJ (Serviço do Prof. Bernardo Couto): *Professores Adjuntos; **Professor Auxillar de Ensino.

*Barbexaclone - Maliasin. Knoll B. A. Produtos Químicos Farmaceuticos. 
A maioria dos pacientes tinha crises convulsivas isoladas tipo Grande Mal (18.90\%). O restante era constituido de um caso (5\%) de crise convulsiva associada a epilepsia do lobo temporal e outro de sindrome de Lennox-Gastaut (5\%). Quanto a posologia empregada, observamos que 13 (65\%) pacientes foram controlados como doses de 100 a $200 \mathrm{mgs}$, sendo que 9 (45\%) com $100 \mathrm{mg}$, um (5\%) com $150 \mathrm{mg}$ e 3 (15\%) com $200 \mathrm{mg}$. Apenas em um caso foi necessária dose de $400 \mathrm{mg}$ diários (Tabela 3). Fstas doses foram atingidas de modo gradual.

Quanto aos efeitos colaterais observados năo se registrou nenhum de maior importáncia que obrigasse à suspensăo da droga. A sonolência leve foi efeito colateral mais comumente observado $(8-40 \%)$, porem regredia com o passar de alguns dias espontaneamente ou com persistência da dose, năo chegando tal efeito a interferir nas atividades dos pacientes de maneira importante. Agitaço leve foi verificada em 3 pacientes (15\%) também passageira e corrigivel com a reducăo da dose. Fm dois casos fol constatada dificuldade no adormecer que fol controlada apenas antecipando em algumas horas a ingeståo do medicamento. Fm um caso observamos tonturas de pequena intensidade; este paciente fazia uso associado de outro antiepiléptico e apresentava distúrbio no comportamento emocional (Tabela 5). Devemos considerar que estes efeitos foram constatados, em geral, no inicio do tratamento e que, ulteriormente, os pacientes năo mais se queixavam de qualquer outro efeito indesejável.

\begin{tabular}{cc}
\hline Idade & Numero de casos \\
\hline 0 a 3 anos & 0 \\
3 a 6 anos & $9(45 \%)$ \\
6 a 9 anos & $3(15 \%)$ \\
9 a 12 anos & $8(40 \%)$ \\
\hline
\end{tabular}

Tabela 1 - Idade e numero dos pacientes

\begin{tabular}{cc}
\hline \multicolumn{1}{c}{ Diagnóstico } & Número de casos \\
\hline \hline $\begin{array}{l}\text { Crise convulsiva do típo GM } \\
\text { Associada com epilepsia do lobo temporal }\end{array}$ & $18(90 \%)$ \\
Sindrome de Lennox & $1(5 \%)$ \\
\hline
\end{tabular}

Tabela \& - Tipos de epilepsia

\begin{tabular}{cc}
\hline Dose de manutençăo & Número de casos \\
\hline $50-100 \mathrm{mg}$. & $12(60 \%)$ \\
$150-200 \mathrm{mg}$. & $4(20 \%)$ \\
$250-300 \mathrm{mg}$. & $3(15 \%)$ \\
Acima de $300 \mathrm{mg}$. & $1(5 \%)$ \\
\hline
\end{tabular}

Tabel s - Posologia de barbexaclane 


\begin{tabular}{|c|c|c|}
\hline Tempo de & ratamento & Número de casos \\
\hline 11 a 15 & meses & $4 \quad(20 \%)$ \\
\hline 16 a 20 & meses & $6(30 \%)$ \\
\hline 21 a 25 & meses & $8 \quad(40 \%)$ \\
\hline 26 a 30 & meses & $2(10 \%)$ \\
\hline
\end{tabular}

Tabela 4 - Duração do tratamento

\begin{tabular}{|c|c|}
\hline Efeitos colaterais & Número de casos \\
\hline Sonolência leve & $8(40 \%)$ \\
\hline Agitação & $3 \quad(15 \%)$ \\
\hline Tontura & $1(5 \%)$ \\
\hline Agitação antes de dormir & $2(10 \%)$ \\
\hline
\end{tabular}

Tabela 5 - Efeitos colaterais

\begin{tabular}{lcl}
\hline Resultados & Número de casos \\
\hline \hline Muito bom & 13 & $(65 \%)$ \\
Bom & 5 & $(25 \%)$ \\
Regular & 2 & $(10 \%)$ \\
\hline
\end{tabular}

Tabela 6 - Resultados em 20 casos

\section{RESULTADOS E COMENTARIOS}

Quanto aos resultados devemos primeiramente considerar que o parametro usado na análise dos mesmos foi essencialmente clínico, isto é, levando em consideraçáo a frequência e a intensida le das crises convulsivas. Portanto consideraremos: como resultado muito bom (MB) a completa ou quase completa remissăo das crises (paciente assintomático); como resultado bom (B) uma grande diminuiçăo da frequência e/ou da intensidade das crises; como regular (R) uma sensivel melhora do quadro, mas persistindo em frequência e/ou intensidades de crises convulsivas; como nulo (N), a năo resposta ou muito discreta resposta ao tratamento.

Assim é que, do grupo de 20 pacientes, 13 responderam muito bem (MB) ao tratamento $(65 \%), 5$ apresentaram resultado considerado bom (B) (25\%) e, dois, resultado regular (10\%). Ao contrário do que constatamos em trabalho anterior, năo tivemos caso algum de resultado nulo. de interesse considerar que aqueles cujos resultados foram regulares $(R)$, eram casos de difícil controle fazendo uso de outras drogas associadamente. Outro dado importante é que dos 13 pacientes com resultados muito bons (MB), $12(60 \%)$ faziam uso exclusivo do barbexaclone (esquema monoterápico) e, destes, $10(50 \%)$ tomaram uma dose média de 100 a $200 \mathrm{mg}$ diárias. Concluimos com isso que, em um periodo maior de observaçăo, o resultado final alcançado é melhor nos casos indicados e a dose média de manutençăo menor em relação à experiência anterior. Como já observamos, nestes pacientes houve melhora do comportamento em cerca de $20 \%$ dos casos. Este aspecto será motivo de estudo mais especifico em outro trabalho.

De acordo com os resultados acima observados, podemos dizer que 0 barbexaclone deve figurar como mais um importante elemento no arsenal tera- 
pêutico das epilepsias, não só da infância como do adulto. Seu uso isolado ou associado a outras drogas do gênero tem indicação especial quando a sonolência surge como efeito colateral.

\section{RESUMO}

São relatados os resultados da observação de 20 casos de epilepsia sob tratamento clínico com o barbexaclone durante um periodo máxima de dois anos e meio (30 meses). Os autores analisam a eficácia terapêutica, assim como a ocorrência de efeitos colaterais. Chamam a atenção alguns casos onde houve melhora concomitante do comportamentơ e redução da dose média de manutenção em relação à experiência anterior.

\section{SUMMARY}

\section{Reavaluation of barbexaclone effects in 20 epileptic patients}

The clinically observed results in 20 patients treated with barbexaclone for a period of $21 / 2$ years are reported. Therapeutic efficiency as well as side effects are discussed. The authors draw attention to the fact that there was a concomintant improvement in the behaviour of some patients and a diminution of maintainence dosage in relation to a previously published trial.

\section{REFERENCIAS}

1. BARZEGAR, B. - Stellung des Maliasin in der Therapie Kindlicher Anfaelle. An. 130 Congresso Internacional de Pediatria (Viena, 28-8 a 4-09-1971). Tomo 12, págs. 299-303.

2. BECKER, B. - Erfahrungen mit dem Antiepileptikum Maliasin. Med. Welt. 19: 577, 1968.

3. CANGER, R. \& WAHL, L. - Die Behandlung der Epilepsie mit Maliasin. Nervenarzt 39: 476, 1968.

4. GOODMAN, L. \& GILMAN, A. - Pharmacological Basis of Therapeutics. The Macmillan Co., New York, 1965, págs. 9 e 13.

5. HEUBECK, H. - Bericht ueber klinische Erfahrungen mit neuen Antiepileptikum. Fortschr Med. $86: 276,1968$.

6. KRUEGER, H. J. \& SCHWARTZ, H. - Klinische Mitteilung zur Epilepsie Therapie mit Maliasin. Med. Welt 14:690, 1965.

7. MERRIT, H. H. - Textbook of Neurology. Lea \& Febiger, Philadelphia, Fourth edition, 1967.

8. MERRIT, H. H. - The treatment of convulsive disorders. Med. Clin. North America 56: 1225, 1972.

9. OLIVEIRA, C.; FERNANDES, I. \& LIMA, J. M. - Ensaio clínico com barbexaclone nas epilepsias. Arq. Neuro-Psiquiatria. (São Paulo) 35:68, 1977.

10. PENIN, H. - Wirkung und Indikation eines neues Antiepileptikum. Dtsch. Med. Wochr. 89:1683, 1964.

11. TCHICALOEF, M. \& PENNETTI, F. - Maliasin, ein neues Antiepileptikum. Med. et Hyg. (Genève) 927:1198, 1970.

Instituto de Neurologia Deolindo Couto - Av. Venceslau Brds 95, Botafogo 20000 Rio de Janeiro, RJ - Brasil. 